\title{
AS RELAÇÕES DE AMIZADE NO CONTEXTO DE EDUCAÇÃO INFANTIL: IMPLICAÇÕES NO PROCESSO DE APRENDIZAGEM E DESENVOLVIMENTO DE CRIANÇAS PEQUENAS
}

\author{
FRIENDSHIP RELATIONSHIPS IN THE CONTEXT OF EARLY CHILDHOOD \\ EDUCATION: IMPLICATION IN THE LEARNING AND DEVELOPMENT PROCESS \\ OF YOUNG CHILDREN.
}

\author{
BARBOSA, Renan Gonçalves ${ }^{1}$ \\ SANTANA, Maria Luzia da Silva²
}

\begin{abstract}
Resumo
A criança durante toda a escolarização passa por vários processos de adaptação, a exemplo de novo ambiente e as novas relações sociais. Nesse sentido, o presente estudo tem o objetivo de discutir a amizade na infância e suas contribuições no processo de aprendizagem e desenvolvimento da criança na Educação Infantil. A partir desta ótica, realizou-se uma pesquisa de cunho bibliográfico sobre o tema, considerando a Educação Infantil e as crianças dessa faixa etária. A partir da perspectiva histórico-cultural foi possível observar que a criação de laços afetivos, denominados de amizade, podem contribuir para o processo de desenvolvimento infantil e auxiliar no ensino-aprendizagem, uma vez que eles se relacionam com o bem-estar social, adaptação e desenvolvimento cognitivo. Também se observou lacuna de pesquisas brasileiras que contemplem a temática, assim estudos empíricos acerca da amizade na infância e suas implicações na aprendizagem poderão contribuir com a Educação Infantil.
\end{abstract}

PalaVRAS-Chave: Amizade; Criança; Educação infantil; Infância; Socialização.

\section{ABSTRACT}

The child throughout schooling goes through various adaptation processes, such as a new environment and new social relationships. In this sense, the present study aims to discuss childhood friendship and its contributions to the child's learning and development process in Early Childhood Education. From this perspective, a bibliographic research was carried out on the subject, considering early childhood education and children of this age group. From the historicalcultural perspective it was possible to observe that the creation of affective bonds, called friendship, can contribute to the child development process and assist in teaching-learning, since they are related to social well-being, adaptation and cognitive development. There was also a gap

1 Universidade Federal de Mato Grosso do Sul - UFMS. Três Lagoas, MS, Brasil. ORCID: https://orcid.org/0000-0002-0279-5068. e-mail: renangoncalvesjb@gmail.com

2 Universidade Federal de Mato Grosso do Sul - UFMS. Campo Grande, MS, Brasil. ORCID: https://orcid.org/0000-0001-5151-3680 e-mail: santanapsi@gmail.com 
DOI: $10.12957 / \mathrm{e}-\mathrm{mosaicos} .2021 .50162$

in Brazilian research that addresses the theme, so empirical studies onchildhood friendship and its implications for learning may contribute to early childhood education.

KEYwORDS: Friendship; child; early childhood education; childhood; socialization.

\section{INTRODUÇÃO}

A Educação Infantil é a primeira etapa da educação básica fundamentada na Lei de Diretrizes e Bases da Educação Nacional (Lei no 9.394/96) que foi conquistada através de muitas lutas e reivindicações. A Educação Infantil, no seu início, teve um caráter assistencialista, mas passou a ser ofertada com o intuito de proporcionar às crianças pequenas uma vivência de interação e desenvolvimento, pautado nos princípios educacionais e práticas pedagógicas nos pilares cuidar, educar e brincar (BRASIL, 1998).

De acordo com as Diretrizes Nacionais para a Educação Infantil (2010), as creches, Centro de Educação Infantil (CEINF) ou pré-escolas, as quais são caracterizadas como espaços institucionais não domésticos, devem educar e cuidar de crianças entre 0 a 5 anos de idade no período diurno, em jornada integral ou parcial, regulados e supervisionados por órgão competente do sistema de ensino e submetidos a controle social.

Nesse sentido, o espaço institucional da Educação Infantil deve ser adequado às demandas das crianças pequenas para promover o seu desenvolvimento social, físico, cultural e cognitivo. As instituições da Educação Infantil, assim como as demais devem assumir responsabilidades para a constituição de uma sociedade livre, respeitando a identidade e a característica de todos, possibilitando uma educação de qualidade, com aspectos que viabilizem conhecimento de si mesma e a interação social (OLIVEIRA, 2010), como o desenvolvimento de vínculos, entre eles de amizade.

A amizade infantil é perpassada pelos elementos históricos, culturais e econômicos e é influenciada pelo contexto imediato de convivência, a exemplo da família, escola e vizinhança, que favorecem a constituição de amizade. $O$ início das relações de amizade entre as crianças acontece com sua inserção na Educação Infantil, sendo que, no ensino fundamental, as amizades continuam a representar um elemento importante de ajustamento da criança. Muitas das relações de amizade das crianças são constituídas com os colegas de sala, e algumas são preservadas mesmo mudando para outros contextos não escolares (GARCIA, 2005).

Assim, na Educação Infantil, são construídas as primeiras relações, sejam elas entre as crianças como também com os adultos que compõem o meio educacional em que estão inseridos. Também surgem as primeiras relações de amizade que, na acepção de Garcia (2005), no contexto da infância é uma forma importante de socialização e contribui para o desenvolvimento afetivo e intelectual. 
DOI: $10.12957 / \mathrm{e}-\mathrm{mosaicos} .2021 .50162$

O ambiente escolar possibilita o desenvolvimento de atividades em grupo, instiga a cooperação entre os pares e promove momentos de brincadeira e recreação, contribuindo para a constituição de vínculos afetivos como nas relações de amizade. A relação de amizade envolve perdão, compaixão, paciência, empatia, altruísmo, gratidão e honestidade, promove comportamentos de cooperação e possibilita a aproximação entre as pessoas. A afinidade, empatia, identidade, compatibilidade, o compartilhar de pensamentos, afetos, sonhos, atividades, conhecimentos, problemas e intimidade, a comunicação e o afeto positivo são elementos presentes nas relações de amizade, o que implica companheirismo, apoio, confiança, proximidade, respeito, lealdade, reciprocidade e disponibilidade (SENA; SOUZA, 2010).

Os estudos na temática da amizade de Garcia (2005), Garcia e Pereira (2008), Wisniewski e Tolentino (2011) apontam que os indivíduos buscam relações de amizade com pares que mais se aproximam quanto as suas características culturais, econômicas e sociais, sendo tais fatores relevantes para construção de amizade. As pesquisas ainda carecem de enfoque dessas relações no que tange as crianças pequenas no contexto de Educação Infantil, justificando assim este estudo.

Sendo assim, este artigo tem o objetivo de discutir a amizade na infância e suas contribuições no processo de aprendizagem e desenvolvimento de criança na Educação Infantil. A partir desta ótica, realizou-se uma pesquisa de cunho bibliográfico que na concepção de Gil (2002) é desenvolvida com base em material já elaborado, constituído principalmente de livros e artigos científicos. Nesse sentido, para o delineamento deste artigo, foram levantados artigos da literatura brasileira e internacional disponíveis em plataformas digitais e revistas que tratam da temática da amizade principalmente no que tange a amizade entre crianças pequenas em fase pré-escolar.

O levantamento de pesquisas nessa temática, considerando sua interlocução com a realidade e a dinâmica de crianças pequenas no contexto de Educação Infantil, foram organizados de maneira a sumariar suas contribuições, refletindo sobre as lacunas de estudos acerca das relações de amizade infantil e seus contributos para o processo de desenvolvimento psicoeducacional de crianças.

\section{As Relações de amizade Na INFÂNCIA E suAs CONTRIBUições PARA O PROCESSO de DESENVOLVIMENTO PSICOEDUCACIONAL DA CRIANÇA}

Os Referenciais Curriculares para a Educação Infantil trazem a concepção de criança como sendo de "natureza singular, que as caracteriza como seres que sentem e pensam o mundo de um jeito muito próprio" (BRASIL, 1998). Essa compreensão é recente e levanta questionamentos frente aos processos de desenvolvimento e socialização delas, principalmente no que tange aos ambientes de Educação Infantil que tem seus olhares 
DOI: $10.12957 / \mathrm{e}-\mathrm{mosaicos} .2021 .50162$

voltados para o educar, cuidar e brincar de crianças na faixa etária de 0 a 6 anos de idade se mostra de suma importância para a sua constituição enquanto indivíduo imerso em uma sociedade marcada por questões, históricas e culturais.

A infância é tema estudado a partir de diferentes correntes teóricas, a exemplo de pesquisas na área da psicologia que consideram os estágios de desenvolvimento da criança, entre os mais conhecidos na área da educação a epistemologia genética do Jean Piaget e a psicogênese da pessoa completa de Henri Wallon que são autores considerados interacionistas. Ainda na linha do interacionismo, os pesquisadores da psicologia sóciohistórica Leontiev, Elkonin e Vigostski contribuem para problematizar a Educação Infantil e a periodização do desenvolvimento psicológico, considerando a "relação da criança com a sociedade construída historicamente a partir das necessidades dos homens" (FACCI, 2004, p. 66).

A psicologia histórico-cultural compreende a criança como sendo uma pessoa ativa, com particularidades e interesses a serem ampliados por meio das relações vivenciadas dentro e fora da instituição escolar infantil (LIMA; SILVA; RIBEIRO, 2010). Nesse sentido, as etapas da Educação Infantil e da infância são períodos em que ocorrem grandes transformações na vida das crianças. Assim, conforme Peloso (2013), a criança vai modificando o mundo e se constituindo à medida que amplia suas funções psicológicas superiores como a afetividade, linguagem, memória dentre diversos outros aspectos, sendo esses de suma importância para o processo de desenvolvimento do psiquismo da criança.

As crianças, nessa etapa da vida, são permeadas por diferentes maneiras de pensar e viver o mundo. Sendo assim, a psicologia histórico-cultural compreende essa infância como sendo um fenômeno que só pode ser compreendido dentro de sua realidade e contexto. Segundo Aquino (2015), a caracterização do pensamento infantil não é a ausência de conhecimento que deve ser corrigida, mas sim de ideias caracterizadas como leituras peculiares do mundo inferidas a partir das relações estabelecidas com o mundo físico e social mediadas pela cultura.

Vygotsky (1994) traz diversas contribuições para a compreensão da formação da psique humana. Em seus escritos, defende a lei genética do desenvolvimento cultural, postulando que "toda função psíquica superior inevitavelmente passa por um estágio externo de desenvolvimento porque a função, no início, é social" (VYGOTSKY, 1994, p. 150). A formação do psiquismo e das funções superiores vão se constituindo a partir das interações sociais e do ambiente/contexto em que a criança se insere, mediados pela cultura. Assim, o desenvolvimento acontece, primeiramente, no coletivo, ou seja, em nível interpessoal/interpsicológico, e posteriormente, no individual/intrapsicológico.

Estes planos de desenvolvimento do psiquismo humano podem ser evidenciados em diversas obras de Vygotsky e seus colaboradores que constituem importantes marcos 
DOI: $10.12957 / \mathrm{e}-\mathrm{mosaicos} .2021 .50162$

teóricos para compreensão do desenvolvimento infantil. A infância nos leva a refletir a respeito dos seus períodos de desenvolvimento, para isso ancorados em Vygotsky e seus colaboradores, em destaque Elkonin (1987 apud LAZARETTI, 2011) será apresentada acerca da periodização do desenvolvimento infantil.

A periodização abrange os níveis e as particularidades de cada idade e período que pode ser compreendido considerando três épocas do desenvolvimento humano constituídas pela primeira infância, infância e adolescência. Lazaretti (2011), em seu livro sobre a vida e obra do psicólogo D. B. Elkonin, relata que cada período possui suas próprias estruturas específicas, únicas e irrepetíveis. $O$ desenvolvimento da criança, nessa perspectiva, não se processa pela passagem de um período ao outro de forma gradual, lenta, sequencial, mas por mudanças essenciais, que são as forças motrizes desse processo.

Ainda para Lazaretti (2011), os períodos do desenvolvimento podem até ter um determinado tempo, mas seus limites estão condicionados por seu conteúdo, que tem dependência direta com as condições concretas em que se desenrola o desenvolvimento da criança. Sendo assim, é importante frisar que a periodização do desenvolvimento da criança na perspectiva da psicologia histórico-cultural não é algo linear e fixo, mas varia de acordo com o contexto sócio-histórico em que a criança convive.

A partir da psicologia histórico-cultural consideram-se os estágios como elemento dinâmico e que não assumem caráter universal. Para essa corrente teórica, "a criança se desenvolve por meio da atividade social, a qual, por sua vez, tem como traço principal a mediação por meio de instrumentos que se interpõem entre o sujeito e o objeto de sua atividade" (FACCI, 2004, p. 65). A periodização proposta por Vygotsky e ampliada por Elkonin (1987 apud LAZARETTI, 2011) e Davdov (1986 apud CAMILO, 2008) pode ser observada no quadro 1.

Quadro 1: A periodização do desenvolvimento da criança segundo a psicologia histórico cultural

\begin{tabular}{|c|l|}
\hline Período & \multicolumn{1}{|c|}{ Principais características } \\
\hline Primeiro ano & $\begin{array}{l}\text { A comunicação emocional direta com os adultos é própria do bebê desde as primeiras } \\
\text { semanas de vida até por volta de um ano aproximadamente. Graças a tal comunicação, no } \\
\text { pequeno se forma a necessidade de comunicação com outras pessoas, uma atitude } \\
\text { emocional para as mesmas, apreensão como base das ações humanas com as coisas, uma } \\
\text { série de ações perceptivas. }\end{array}$ \\
\hline $\begin{array}{l}\text { Primeira } \\
\text { infância }\end{array}$ & $\begin{array}{l}\text { A atividade objetal é característica da criança entre cerca de um e três anos } \\
\text { aproximadamente. Realizando a atividade de manipulação de objetos (primeiro em } \\
\text { colaboração com os adultos como parceiros mais experientes), a criança reproduz os } \\
\text { procedimentos de ação com os objetos, elaborados socialmente; surge a linguagem, a } \\
\text { designação com sentido dos objetos, a percepção categorial generalizada do mundo } \\
\text { objetal e o pensamento concreto em ações. A neoformação central desta idade é o } \\
\text { surgimento na criança da consciência. }\end{array}$ \\
\hline
\end{tabular}


DOI: $10.12957 / \mathrm{e}-\mathrm{mosaicos} .2021 .50162$

\begin{tabular}{|c|l|}
\hline $\begin{array}{c}\text { Idade pré- } \\
\text { escolar }\end{array}$ & $\begin{array}{l}\text { A atividade de jogo é a mais característica para a criança por volta de três a seis anos } \\
\text { aproximadamente. Em sua realização surge no pequeno a imaginação e a função } \\
\text { simbólica, a orientação no sentido geral das relações e ações humanas; também se } \\
\text { formam as vivências generalizadas e a orientação consciente. }\end{array}$ \\
\hline
\end{tabular}

Fonte: Adaptado (CAMILO, 2008 p. 134-135)

A partir do exposto acima, pode-se inferir que o processo de socialização do bebê se inicia muito cedo. Desde o nascimento ele já se comunica com as pessoas que o rodeiam, expressando através do rosto, entonação do choro e diversos outros elementos que possibilitam uma exposição dos sentimentos relacionados ao seu bem-estar (CHEROGLU; MAGALHÃES, 2016). Nesse sentido, as formas de socialização do bebê giram em torno dos adultos que a cercam e interagem com ele, sendo que a comunicação remete a satisfação de suas necessidades biológicas.

A partir do momento que a criança se apropria da linguagem falada, por volta do primeiro ano de idade, o processo de socialização adquire um novo caráter. Com o desenvolvimento da linguagem ela começa a se relacionar no mundo utilizando o pensamento, fazendo o uso da linguagem como elemento de comunicação e generalização. É um salto qualitativo no seu desenvolvimento psicológico e social que the possibilita novas teias de socialização e de relações com outros indivíduos:

[...] o momento de maior significado no curso de desenvolvimento intelectual, que dá origem às formas puramente humanas de inteligência prática e abstrata, acontece quando a fala e a atividade prática, então duas linhas completamente independentes de desenvolvimento, convergem (VYGOTSKY, 1994, p. 12).

A partir dos dois e três anos de idade, os processos de socialização dessa criança sofrem mudanças uma vez que se inicia o processo de escolarização, com a sua inserção em outro contexto de desenvolvimento. Facci (2004) sinaliza que a vida da criança muda muito quando ela entra no ambiente de educação, em que a relação com os professores faz parte de um pequeno e íntimo círculo de seus contatos e também através do processo de interação dela com seus pares. Na infância acontecem os primeiros contatos recíprocos com o ambiente, a cultura e o mundo que a criança está inserida, também acontecem as primeiras relações sociais que favorecem a constituição da relação de amizade.

O estudo de Silva e Garcia (2008) focalizando a perspectiva materna aponta que, a partir do primeiro ano de vida, as crianças já sinalizam as suas primeiras relações entre pares, que são proporcionadas à medida que a família possibilita a criança o contato com outras crianças e adultos. Para que esses relacionamentos ocorram devem ser 
DOI: $10.12957 / \mathrm{e}-\mathrm{mosaicos} .2021 .50162$

proporcionadas situações de brincadeiras, a fim de que aconteçam interações regulares entre as crianças e elas estejam suficientemente familiarizadas para construir vínculos de amizade (SILVA; GARCIA, 2008).

Nessa direção, Merizio, Garcia e Pontes (2008) sinalizam que a tríade brincar, relações interpessoais e cultura são indissociáveis como elementos dialeticamente relacionados e que se afetam mutuamente. E apontam a brincadeira como um dos elementos fundamentais na construção dessas relações de amizade, principalmente, no contexto da infância que a atividade compartilhada cria espaços privilegiados para a construção de relacionamentos cada vez mais complexos, especialmente a amizade.

O ambiente social provê à criança habilidades necessárias para brincar com seus pares e, por outro lado, a brincadeira age como um importante contexto no qual a criança adquire habilidade e conhecimento social. Desse modo, a prática social afeta a brincadeira da criança, dirigindo para valores e normas culturalmente específicas (MERIZO; GARCIA; PONTES, 2008, p. 124).

Com o passar do tempo, as relações entre os pares se tornam mais fortes e marcadas principalmente por conta do processo de escolarização, que a depender da cultura em que a criança está inserida, se inicia cedo. Essas relações, caracterizadas como amizade, levam em consideração alguns aspectos relacionados a atributos demográficos, comportamentais, acadêmicos e sociais sendo identificada como a base para as amizades infantis (GARCIA, 2005). Há indícios de que quanto maior for a aproximação destes fatores, maior será a possibilidade da construção de uma relação de amizade (GARCIA, 2005).

Crianças em idade pré-escolar já nomeiam seus amigos cujas relações se dão de maneira natural e recíproca. Garcia (2005) sinaliza que a reciprocidade, usualmente, costuma ser considerada outra dimensão básica das amizades. Consideram-se amigas as crianças que se nomeiem reciprocamente como tais. A compreensão acerca da amizade sofre modificações no decorrer do desenvolvimento infantil.

As concepções de amizade avançam do concreto para o abstrato com a idade, o que se reflete em seu comportamento com os amigos. Com a idade, as amizades das crianças demonstram mais estabilidade, mais altruísmo recíproco e mais conhecimento pessoal íntimo. Os amigos participam de mais tipos diferentes de interações do que não amigos. As crianças em processo de fazer amigos têm maior probabilidade de se comunicar claramente, se auto revelar mais frequentemente e resolver 
DOI: $10.12957 / \mathrm{e}-\mathrm{mosaicos} .2021 .50162$

mais eficazmente conflitos. Embora conflitos ocorram frequentemente, dentro das amizades, estes são resolvidos por amigos de maneira a aumentar a probabilidade de continuação do relacionamento (GARCIA; PEREIRA, 2008, p. 26).

Crianças em idade menos avançada relacionam a amizade ao fato de não fazerem mal ao amigo, as maiores à possibilidade de estarem próximas, de realizarem atividades juntas; acontecendo a alteração de uma ideia mais simplista e egocêntrica para o ideal de empatia e companheirismo. Os amigos das crianças geralmente são do cotidiano delas, incluindo o contexto de educação, a vizinhança e os bairros próximos e tem como principal atividade as brincadeiras (RICARDO, 2011). As interações preferenciais entre as crianças pequenas em relação às demais são indicadores da relação de amizade, além disso, "crianças que são amigas percebem o outro como um parceiro de brincadeiras" (SILVA; GARCIA, 2008, p. 593).

A brincadeira se revela então como sendo o primeiro modo de socialização e de criação de laços afetivos entre essas crianças. Vygotsky (1994) situa que na brincadeira, "o pensamento está separado dos objetos, e a ação surge das ideias e não das coisas". Isso remete as situações cotidianas de brincadeira nos ambientes de Educação Infantil em que essas crianças muitas vezes compartilham sua imaginação e visão dos brinquedos. Quando essa relação ocorre entre pares é possível observar a construção de uma relação de amizade.

Questões étnicas e de similaridade são observadas na construção de relações de amizade entre crianças neste período de desenvolvimento. A criança, mesmo que inconscientemente, procurará uma criança que mais se pareça em aspectos comportamentais, de gênero e até mesmo aspectos demográficos para se relacionar. Garcia (2005) caracteriza esses elementos como sendo elementos de similaridade, fator determinante para a construção de laços afetivos caracterizados como amizade:

Amigos são similares em relação ao outro em habilidades, atitudes e estilo de vida. Estas similaridades derivam da seleção de amigos e da mútua socialização que ocorre uma vez que duas crianças tenham se tornado amigas. As crianças e seus amigos são mais parecidos entre si (similares), do que não amigos, em comportamento pró-social, antissocial, timidez e dependência, status sociométrico e sintomas depressivos. As similaridades nas amizades variam de atributo para atributo, sendo maior no comportamento antissocial que em outros domínios (GARCIA, 2005, p. 10).

No período da infância, a criança já busca estratégias de influências sociais, uma vez que questões relacionadas à popularidade de determinada criança também é um fator 
DOI: $10.12957 / \mathrm{e}-\mathrm{mosaicos} .2021 .50162$

relevante nas relações de amizade. Existe uma constante consideração do estado de ego da criança frente aos seus amigos, recorrendo as duas estratégias: as crianças podem manter uma autoavaliação positiva por meio de escolhas apropriadas de amigos, percebendo diferenças reais de desempenho (crianças com baixa autoestima); ou podem distorcer essas diferenças para acentuar a auto avaliação (possivelmente em crianças com alta autoestima) (GARCIA, 2005).

Nesse sentido, é importante pensar no quanto a construção dessas relações no contexto de Educação Infantil pode contribuir no processo de escolarização, adaptação, assim como no processo de ensino-aprendizagem das crianças inseridas nessas instituições, uma vez que toda função psíquica superior acontece, primeiro no coletivo e social, para então se tornar função individual. Na instituição escolar a criança está em um ambiente de integração social em que há atividades compartilhadas, em vista disso, estas atividades ajudam as crianças a internalizar os modos de pensamento e comportamento da sociedade (SOUZA et al. 2013).

\section{AMIZADE E EDUCAÇÃO: UMA INTERFACE PERTINENTE}

As crianças pequenas inseridas no contexto de Educação Infantil estão em contato direto com um mundo alheio ao contexto familiar. Sendo assim, elas experimentam um universo de possibilidades de desenvolvimento mediante a sua interação nesse ambiente, com seus pares e adultos. Nesse contexto também se iniciam as relações que ultrapassam a ideia de coleguismo, a qual denomina de suas primeiras relações de amizade. Segundo Garcia (2005) as relações com um amigo têm características particulares, carregam os princípios da reciprocidade e atividade social mais intensa, se diferenciando das relações com os não amigos (colegas) na infância.

As relações entre pares no contexto de Educação Infantil contribuem para o processo de socialização e adaptação escolar. Nesse sentido, Wisniewsky e Tolentino (2011) sinalizam que o fator de socialização e amizade pode promover de maneira positiva ou negativamente as relações interpessoais e intrapessoais da criança, sendo que a reciprocidade com os pares possibilita o desenvolvimento cognitivo e pessoal se constituindo como elemento motivador dessas relações.

Essas relações na Educação Infantil, muitas vezes são tecidas no momento da brincadeira, tendo em vista que esse elemento é fundamental e indispensável nesse período da educação e do seu desenvolvimento por compreender que a tarefa da infância é brincar. Garcia (2005) aponta que o conjunto das afinidades são possibilitadas através da brincadeira, e se constrói num contexto de relações afetivas e interacionais variadas que nem sempre são harmônicas, especialmente no que refere à brincadeira social. Isso 
DOI: $10.12957 / \mathrm{e}-\mathrm{mosaicos} .2021 .50162$

possibilita pensar que as crianças, mesmo brincando estão construindo sua teia de relações sejam elas recíprocas ou não.

A partir da discussão filosófica da amizade, tomando-a como o exercício da ética e da política no contexto educacional, Carvalho (2015) considerou-a fundamental para construir uma boa relação perante a pluralidade, a diversidade e a singularidade presentes na sala de aula. A amizade pode ser uma prática e uma maneira de transformar a sala de aula num espaço aberto a relações intersubjetivas renovadas, além de uma saída para amenizar as situações de violência e conflitos escolares (CARVALHO, 2010). A amizade beneficia a boa convivência, a criação de vínculos, a vida feliz, alegre e prazerosa, podendo contribuir para a partilha de vivências tristes, alegres e promover as relações de confiança (CARVALHO; LUENGO, 2017).

As investigações acerca da amizade ancoradas na perspectiva da ética e política (CARVALHO, 2010, 2015; CARVALHO; LUENGO, 2017) possibilitam sugerir que a relação de amizade entre os pares em contexto de educação é um recurso relevante para o desenvolvimento das crianças pequenas, contribuindo sobremaneira para a constituição da autonomia, comportamentos pró-sociais voluntários, relações interpessoais e interculturais positivas, marcadas pela empatia, pelo sentimento de solidariedade e cooperação.

Esses princípios estão presentes sobremaneira no contexto de Educação Infantil, uma vez que essas crianças estão em processo de desenvolvimento e conhecimento de mundo. Ter um amigo nesse período de primeira infância pode ser capaz de prevenir problemas psicológicos como depressão e ansiedade, proporcionando bem-estar psicológico mediante ajuda de todo tipo, confidência, proteção contra medos e situações estranhas, bem como valorizar às características pessoais do amigo (SOUZA; SILVEIRA; ROCHA, 2013).

Apesar de ser uma temática de extrema importância para o processo de escolarização dessas crianças, ainda existe uma carência de pesquisas nesta área, uma vez que conforme Garcia (2005) o tema começou a ser explorado no Brasil nos últimos vinte anos. Alguns estudos realizados sobre a temática nos possibilitam pensar a respeito da construção dessas relações de amizade na infância, bem como suas contribuições para as práticas pedagógicas envolvendo crianças pequenas.

O estudo de Silva e Garcia (2008), com 20 mães de crianças em período pós-natal, com idades entre 24 a 48 anos, apontou que elas relatam relações de amizade entre os bebês, relações estas marcadas por sentimentos e expressões ao ver e sentir a presença da outra criança ou adulto (amigo). Para além disso, os autores também observaram que as amizades dos pais disponibilizavam contatos com os filhos dos amigos, favorecendo a criação desses laços, assim constataram que relações consideradas de amizade já conseguem ser observadas nesse período do desenvolvimento humano. 
DOI: $10.12957 / \mathrm{e}-\mathrm{mosaicos} .2021 .50162$

Ainda relatando acerca dessa temática, Costa (2012) descreveu as amizades na história de vida de imigrantes gregos vivendo no Espírito Santo, com outros gregos, brasileiros ou outros estrangeiros, incluindo também amizades interculturais e o papel das amizades no processo de adaptação ou ajustamento à vida no Brasil. Para tal, utilizou-se da entrevista com 10 imigrantes gregos que vieram para o Brasil com 11 anos de idade ou mais. A partir de seus dados, notou-se, que a amizade atua como mediadora da adaptação do estrangeiro ao novo país - apesar das suas variações culturais representando não somente uma condição atuante nas diversas tradições, mas permitindo a comunicação entre esses costumes, contribuindo para que imigrantes se sintam acolhidos no seio cultural da nação que escolheram para viver.

Recentemente, Valadeiro (2017) realizou um estudo referente as relações de amizade entre crianças no contexto de creche, para compreender o papel das amizades. Para isso, realizou uma investigação-ação tendo as práticas pedagógicas dos professores como agentes promotores e moderadores do desenvolvimento das crianças. Os achados apontam que as interações e as brincadeiras, entre as crianças, são essenciais para elas refletirem sobre a melhor forma de coordenar as suas ações para com os outros, considerando o respeito e reconhecendo sentimentos, desejos e interesses comuns. As amizades são relações que exigem de nós uma total entrega e saber ser empáticos sendo fundamental para as crianças (VALADEIRO, 2017).

Apesar da literatura brasileira apresentar poucos estudos na temática da amizade na infância e educação, a literatura internacional traz alguns elementos que ajudam discutir a amizade em contextos de educação. Nesse viés, Melero e Fuentes (1992) realizaram um estudo a respeito do desenvolvimento das relações de amizade na infância e possibilidades de intervenção escolar, a pesquisa reuniu diversos estudos na temática caracterizando-se como um estudo de caráter bibliográfico.

Os achados possibilitaram apontar que "as relações de amizade permitem às crianças ampliar seus sentimentos e valores tanto positivos quanto negativos e, dessa maneira, contribuem para o controle emocional" (MELERO; FUENTES, 1992, p. 57). As relações de amizade e o intercâmbio social influenciam de maneira favorável as estruturas do pensamento moral e também ajudam as crianças dominar impulsos agressivos. As crianças necessitam de relações que sejam de qualidade em níveis de comunicação e afeto (MELERO; FUENTES, 1992).

Com relação às práticas pedagógicas o papel do professor é relevante, podendo contribuir de maneira significativa para que as relações de amizade possam ocorrer. Conforme Melero e Fuentes (1992), alguns aspectos por parte dos professores têm incidência decisiva na formação de relações de amizade, sendo elas a atitude tolerante e democrática do professor, a quantidade de crianças por turma e os tipos de atividades realizadas por esse professor no contexto de sala de aula. 
DOI: $10.12957 /$ e-mosaicos.2021.50162

Também sobre a amizade em contexto de educação, Farfán (2012) realizou uma pesquisa com 29 crianças de uma turma de $4^{\circ}$ ano do ensino fundamental de uma escola no Peru, utilizando o gênero textual conto como uma estratégia útil para treinar os valores de generosidade e amizade entre as crianças. Para isso, utilizou testes para medir o nível de amizade e generosidade. No primeiro teste observou-se que mais de $50 \%$ das crianças obtiveram um nível baixo ou regular na constituição do valor da amizade, enquanto que $13,8 \%$ atingiu o nível bom. Foi trabalhado com esse tema em sala de aula devido à existência de uma relação de divisão entre as crianças (FARFÁN, 2012, p. 139).

Com relação à generosidade, a maioria das crianças apresentou nível baixo ou regular na prática do valor da generosidade. A causa desse resultado pode ter relação com a ausência de oportunidades para exercer esse valor. Essa pesquisa contribuiu para pensar em como as práticas dos professores são relevantes para a formação de níveis mais elevados de amizade e generosidade, uma vez que após seis semanas de trabalhos com os contos, os níveis de amizade e generosidade aumentaram. Assim, os contos contribuíram de maneira positiva e significativa para a elevação desses níveis. (FARFÁN, 2012).

Outra pesquisa que amplia a discussão sobre a amizade na educação foi realizada por García Barcete et.al (2013) sobre um programa de aprendizagem da amizade, voltado para crianças em condição de rejeição. O programa consiste em 9 sessões de jogos em pares, como única regra as crianças devem fazer um acordo em escolher, mudar ou finalizar o jogo de maneira respeitosa.

Além disso, as atividades realizadas pelo programa de aprendizagem da amizade contam com uma formação para os pais de crianças em condição de rejeição, um estudante com dificuldades sociais, cinco ou seis companheiros de classe e um adulto facilitador (GARCÍA BARCETE et al. 2013). Necessitam ser realizadas ao mínimo 9 sessões com a composição acima descrita para que se obtenham os resultados. Os achados sinalizaram que este tipo de metodologia é de grande eficácia para que sejam minimizados problemas referentes a crianças em situação de rejeição em contextos escolares, que são marcados pelas relações de amizade.

A pesquisa de Rabaglietti, Vacirca e Pakalniskiene (2013), com 177 crianças entre 6 a 9 anos, observou os efeitos de acompanhamento de certos componentes da competência socioemocional das crianças (por exemplo, comportamento pró-social e falta de autorregulação comportamental) e características da amizade em termos de qualidades positivas e negativas e extensão da rede de amizade. A metodologia foi organizada em dois momentos; no primeiro, abrangeu essa faixa etária descrita e o outro aconteceu um ano após a primeira, na coleta de dados usou as escalas de qualidade de amizade para medir a autorregulação e os afetos positivos entre as crianças. 
DOI: $10.12957 / \mathrm{e}-\mathrm{mosaicos} .2021 .50162$

Os resultados apontaram que a autorregulação, isto é, a capacidade do indivíduo de planejar e avaliar seus sentimentos, pensamentos, etc., afetou a qualidade positiva e/ou negativa das relações de amizade. Os modelos indicaram que o comportamento pró-social das crianças afeta amizade positiva enquanto a falta de autorregulação afeta qualidade de amizade negativa ao longo do tempo. As crianças que se comportam melhor tendem a ter melhores qualidades nas amizades, enquanto as que não demonstraram controle do seu próprio comportamento tenderam a desenvolver relações de amizade de qualidade negativa. Ainda cabe salientar que a dimensão de amizade com qualidade positiva está ligada ao apoio e a confiança, enquanto a dimensão negativa está ligada principalmente ao conflito (RABAGLIETTI; VACIRCA; PAKALNISKIENE, 2013).

O estudo de Carter e Nutbrown (2016) buscou compreender a percepção de crianças em relação a amizade e, para isso, realizaram entrevistas, brincadeiras e dramatizações com 7 crianças de 5 anos. A análise dos dados apontou que as crianças mostraram considerável compreensão emocional em relação à amizade, sendo que suas experiências de amizade são diferentes de uma perspectiva adulta. As crianças compartilharam muitos aspectos únicos de sua cultura de pares, incluindo regras, rotinas, preocupações e práticas que muitas vezes são alheios aos adultos.

Também Carter e Nutbrown (2016) chamaram a atenção para a importância da criação de uma pedagogia da amizade, uma vez que estas relações foram sinalizadas pelas crianças como sendo um dos fatores de satisfação e bem-estar em contexto de educação. Para além disso, sinalizam que a instituição de educação deverá oferecer e proporcionar a estas crianças, tempo e ambientes para que as relações de amizade sejam favorecidas e fortalecidas.

Os estudos sumariados possibilitam sugerir que as relações de amizade no contexto de Educação Infantil são importantes para o bem-estar de crianças, influenciando o seu processo de desenvolvimento em aspectos físicos, cognitivos e psicossociais. Nesse sentido, cabe à Educação Infantil voltar seus olhares com o intuito de instigar a amizade entre as crianças pequenas. Os estudos de Garcia (2005) sinalizam que, muitas vezes, relações de amizade que são construídas na infância, permanecem durante toda a vida do indivíduo. A troca entre as crianças é um momento que deve ser pensado de forma que as crianças possam comunicar-se e expressar-se, demonstrando seus modos de agir, de pensar e de sentir, em um ambiente acolhedor e que propicie a confiança e a autoestima (BRASIL, 1998).

Esse aspecto corrobora com a importância de problematizar, com professores e demais responsáveis que trabalham com crianças na Educação Infantil, acerca de como eles podem favorecer a interação e o contato entre as crianças para lhes possibilitar a criação de laços afetivos de amizade. Os estudos Carter e Nutbrown (2016), Valadeiro (2017), Costa (2012) apresentam um panorama do quanto essas relações são importantes 
DOI: $10.12957 / \mathrm{e}-\mathrm{mosaicos} .2021 .50162$

para desenvolvimento das crianças e também evidenciam a relevância de práticas docentes para a promoção de relações de amizade positivas.

A partir dos estudos levantados, pode-se inferir que a literatura internacional se mostra mais ampliada nos estudos relacionados à temática, ao se considerar a disponibilidade de pesquisas brasileiras. Contudo, há carência de estudos que busquem compreender a construção das relações de amizade na infância, considerando os seus diferentes contextos de desenvolvimento, cultura e idades.

Voltar os olhares para a realização de pesquisas nessa temática é contribuir sobremaneira para que o processo de escolarização dessas crianças possa ocorrer de maneira mais prazerosa, uma vez que os estudos mostram que crianças em ambientes favoráveis às construções de laços afetivos conseguem desenvolver-se de maneira mais positiva. Nesse sentido, é importante que essa temática não passe despercebido pelos professores e pesquisadores da Educação Infantil, uma vez que as relações de amizade se iniciam nessa etapa da educação.

\section{CONCLUSÃo}

O objetivo desse artigo foi discutir a amizade na infância e suas contribuições no processo de aprendizagem e desenvolvimento de crianças na Educação Infantil e para isso utilizou a pesquisa bibliográfica. Apesar dos estudos relacionados à amizade no contexto de Educação Infantil serem poucos, foi possível compreender que a amizade é um dos elementos favorecedores do processo de aprendizagem e desenvolvimento positivo da criança, uma vez que há o sentimento de reciprocidade entre os envolvidos, que abrange princípios como o companheirismo, cooperação, empatia e o compartilhamento de atividades e de situações.

Quando nos remetemos às salas de atividades no contexto de Educação Infantil, podemos ter um panorama do quão rico são esses espaços no que tange as possibilidades para constituição de relação de amizade. Sendo assim, compreender como ocorre a criação desses laços é de suma importância devendo estar presente na formação de professor, assim terá subsídios teóricos para práticas que enriqueçam e favoreçam a construção de laços de amizade positiva. A partir dos estudos levantados, é possível refletir a respeito do papel do professor, no que tange à criação de elementos favoráveis de laços de amizade entre as crianças, pois é um elemento importante para que sejam evitados conflitos e relações negativas.

Além disso, a discussão das relações de amizade a partir da leitura da psicologia histórico-cultural demonstra o quanto a cultura influencia na construção desses laços, uma vez que a amizade é perpassada pelos elementos vivenciados em cada contexto. A 
DOI: $10.12957 /$ e-mosaicos.2021.50162

discussão em torno da periodização do desenvolvimento infantil contribuiu para compreensão da construção da amizade, ao se considerar que o contexto influencia a formação social, cognitiva, emocional e cultural na infância e idade pré-escolar, em que as crianças estão tendo um contato mais amplo com contextos alheios ao contexto familiar, sobretudo nas instituições de Educação Infantil.

A partir desse estudo, aponta-se a necessidade de pesquisas voltadas para investigação das influências culturais nos laços de amizade no contexto de Educação Infantil, assim como nas práticas pedagógicas e suas implicações positivas e/ou negativas no processo de criação dessas relações. Neste mesmo caminho, seria importante voltar os estudos para crianças em condição de inclusão, migração ou mesmo crianças marginalizadas socialmente. As pesquisas futuras podem contribuir para que sejam reduzidos os efeitos da desigualdade, da rejeição do diferente e a promoção de uma educação inclusiva.

\section{REFERÊNCIAS}

AQUINO, Ligia Maria Leão de. Contribuições da teoria histórico-cultural para uma educação infantil como lugar das crianças e infâncias. Revista de Psicologia, Rio de Janeiro, v. 27, n. 1, p. 39-43, 2015.

BRASIL. Ministério da Educação. Secretaria de Educação Básica. Diretrizes Curriculares Nacionais para a Educação Infantil. Secretaria de Educação Básica. - Brasília: MEC, SEB, 2010.

BRASIL, M. E. C. Secretaria de Educação Fundamental. Referencial curricular nacional para a educação infantil, v. 1, 2, 3, 1998.

CARTER, Caron; NUTBROWN, Cathy. A Pedagogy of Friendship: young children's friendships and how schools can support them. International Journal of Early Years Education, v. 24, n. 4, p. 395-413, 2016. Disponível em: < https://www.tandfonline.com/doi/abs/10.1080/09669760.2016.1189813 Acesso em janeiro de 2019.

CAMILO, Telma Cristina. A periodização do desenvolvimento infantil: contribuições da teoria histórico-cultural. Revista de Iniciação Científica da FFC, v. 8, n. 2, p. 130-139, 2008. Disponível em: http://www2.marilia.unesp.br/revistas/index.php/ric/article/download/192/176/0 . Acesso em abril de 2019. 
DOI: $10.12957 / \mathrm{e}-\mathrm{mosaicos} .2021 .50162$

CHEROGLU, Simone; MAGALHÃES, Gisele Modé. O primeiro ano de vida: vida uterina, transição pós natal e atividade de comunicação emocional direta com o adulto. In: MARTINS, Lígia Márcia; ABRANTES, Angelo Antonio; FACCI, Marilda Gonçalves Dias (Orgs). Periodização histórico-cultural do desenvolvimento psíquico do nascimento à velhice. Campinas, SP: Autores Associados, 2016.

CARVALHO, Alonso Bezerra de. A relação professor-aluno e a amizade na sala de aula: por uma outra formação humana na escola. Revista Espaço Acadêmico, v. 14, n. 169, p. 2333, 2015. Disponível em:

https://periodicos.ufsm.br/educacaoespecial/article/view/28081/pdf. Acesso em: 10 jan. 2019.

CARVALHO, Alonso Bezerra de. Alteridade e amizade na educação: a sala de aula como espaço ético. In: CONGRESSO INTERNACIONAL DE FiLOSOFIA E EdUCAÇÃo, V., 2010, Caxias do Sul. Anais Congresso Internacional de Filosofia e Educação, Caxias do Sul: Universidade de Caxias do Sul, 2010. Disponível em: https://www.ucs.br/.../Alteridade\%20e\%20amizade \%20na\%20educacao_a\%20sala\%20Acesso em: 10 jan. 2018.

CARVALHO, Alonso Bezerra de; LUENGO, Fabiola Colombani. A amizade na sala de aula e a educação inclusiva: reflexões filosóficas. Revista Educação Especial, v. 30, n. 59, 2017. Disponível em: https://periodicos.ufsm.br/educacaoespecial/article/view/28081/pdf. Acesso em: 29 nov. 2017.

COSTA, Lorena Queiroz Merizio. Amizades interculturais - um estudo com gregos no Espírito Santo. Tese (Doutorado em Psicologia) - Centro de Ciências Humanas e Naturais, Universidade Federal do Espírito Santo. Vitória, p. 249, 2012. Disponível em: http://repositorio.ufes.br/handle/10/3146. Acesso em janeiro de 2019.

FACCI, Marilda Gonçalves Dias. A periodização do desenvolvimento psicológico individual na perspectiva de Leontiev, Elkonin e Vigotski. Cadernos Cedes, v. 24, n. 62, p. 64-81, 2004. Disponível em: < http://www.scielo.br/pdf/ccedes/v24n62/20092.pdf. Acesso em janeiro de 2018

FARFÁN, Mitzy Anilú Herrera. El cuento como estrategia para formar en los valores de amistad y generosidad a los alumnos de cuarto grado " $A$ " del colegio "Lomas de Santa María". Tesis de pregrado en Educación, nivel primaria. Facultad de Ciencias de la Educación, Universidad de Piura. Piura, Perú, p.165, 2012. Disponível em: https://pirhua.udep.edu.pe/handle/11042/1731 Acesso em janeiro 2018.

GARCIA, Agnaldo. (2005). Psicologia da amizade na infância: uma introdução. Vitória: UFES. Disponível em https://agnaldogarcia.files.wordpress.com/2010/12/agnaldo_garcia__livro-psicologiada-amizade-na-infc3a2ncia.pdf. Acesso em setembro de 2018 
DOI: $10.12957 /$ e-mosaicos.2021.50162

GARCÍA BACETE, Francisco Juan et al. El aprendizaje de la amistad en la Educación Primaria. Un procedimiento intensivo para ayudar a los niños rechazados a hacer amigos. Revista Apuntes de Psicología. 2013, Vol. 31, número 2, págs. 155-163. Disponível em: http://repositori.uji.es/xmlui/handle/10234/86770. Acesso em abril de 2019.

GARCIA, Agnaldo Garcia; PEREIRA, Paula Coimbra da Costa. Amizade na infância: um estudo empírico. PSIC - Revista de Psicologia da Vetor Editora, v. 9, no 1, p. 25-34, Jan./Jun. 2008. Disponível em: < http://pepsic.bvsalud.org/pdf/psic/v9n1/v9n1a04.pdf>. Acesso em outubro de 2018.

GIL, Antonio Carlos. Como elaborar projetos de pesquisa. São Paulo, v. 5, n. 61, p. 16-17, 2002.

LAZARETTI, Lucinéia Maria. D. B. Elkonin: vida e obra de um autor da psicologia históricocultural. São Paulo: Editora Unesp, 2011. Disponível em:

http://hdl.handle.net/11449/113668. Acesso em outubro de 2018.

LIMA, Elieuza Aparecida de; SILVA, Ana Laura Ribeiro da; RIBEIRO, Aline Escobar Magalhães. Reflexões sobre a educação infantil: contribuições da teoria histórico-cultural. Revista Interfaces, p. 16-20, 2010. Disponível em:

https://repositorio.unesp.br/handle/11449/115124. Acesso em abril de 2019

MELERO, Maria Angeles; FUENTES, María Jesus. Las amistades infantiles: desarrollo, funciones y pautas de intervención en la escuela. Revista Investigación en la Escuela, 16, 55-67., 1992. Disponível em: https://idus.us.es/xmlui/handle/11441/59480. Acesso em abril de 2019.

MERIZIO, Lorena Queiroz; GARCIA, Agnaldo; PONTES, Fernando Augusto Ramos. Brincadeira e amizade na infância: lembranças de imigrantes libaneses vivendo no Brasil. Gerais: Revista Interinstitucional de Psicologia, 1(2), 2008. Disponível em: http://www.fafich.ufmg.br/gerais/index.php/gerais/issue/view/2. Acesso em março de 2019.

OLIVEIRA, Zilma de Moraes Ramos de. O currículo na educação infantil: o que propõem as novas Diretrizes Nacionais? In: 1., 2010, Seminário Nacional: Currículo em Movimento Perspectivas Atuais, Belo Horizonte. Anais [...]. Belo Horizonte, 2010. Disponível em: https://amavi.org.br/sistemas/pagina/setores/educacao/freiavi/arquivos/2014/ O_Curriculo_na_Educacao_Infantil.pdf Acesso em setembro de 2018.

PELOSO, Franciele Clara. Infância e crianças: contribuições da teoria Histórico-cultural de Vygotsky para compreender a Criança como sujeito histórico e social. IN: XI Congresso 
DOI: $10.12957 / \mathrm{e}-\mathrm{mosaicos} .2021 .50162$

Nacional de Educação, Anais do XI EDUCERE. Curitiba. 2013. Disponível em: http://educere.bruc.com.br/arquivo/pdf2013/7816_5530.pdf. Acesso em abril de 2019.

PEREIRA, Fábio Nogueira; GARCIA, Agnaldo. Amizade e Escolha Profissional: um Estudo com Alunos de Escolas Particulares e Públicas. Pesquisas e Práticas Psicossociais 4(1), São João del-Rei, Dez. 2009. Disponível em:

https://agnaldogarcia.files.wordpress.com/2010/12/pereira_e_garcia.pdf Acesso em abril de 2019.

RABAGLIETTI, Emanuela; VACIRCA, Maria Fernanda; PAKALNISKIENE, Wilmante. Socialemotional competence and friendships: Prosocial behaviour and lack of behavioural selfregulation as predictors of quantity and quality of friendships in middle childhood.

European Journal of Child development, Education and Psychopathology, v. 1, n. 1, p. 520, 2013. Disponível em: https://dialnet.unirioja.es/servlet/articulo?codigo=5761686. Acesso em abril de 2019.

RICARDO, Lorena Santos; ROSSETTI, Claudia Broetto. O conceito de amizade na infância: uma investigação utilizando o método clínico. Constr. psicopedag., São Paulo, v. 19, n. 19, p. 82-94, 2011. Disponível em http://pepsic.bvsalud.org/scielo.php? script=sci_arttext\&pid=S1415-69542011000200007\&lng=pt\&nrm=iso. Acesso em: 02 jan. 2019

SENA, Soraya de Souza. SOUZA, Luciana Karine de. Amizade, infância e TDAH. Contextos Clínicos, v. 3, n. 1, p. 18-28, 2010. Disponível em: < http://www.revistas.unisinos.br/index.php/contextosclinicos/article/view/4558. Acesso em janeiro de 2018

SILVA, Glauce Reis da; GARCIA, Agnaldo. Os primórdios da amizade na infância: a perspectiva materna. Paidéia (Ribeirão Preto), Ribeirão Preto, v. 18, n. 41, p. 591-604, dez. 2008. Disponível em: http://www.scielo.br/scielo.php? script=sci_arttext\&pid=S0103-863X2008000300014\&Ing=en\&nrm=iso. Acesso em: 02 jan. 2018. http://dx.doi.org/10.1590/S0103-863X2008000300014

SOUZA, Luciana Karine de; SILVEIRA, Danielle Cristina; ROCHA, Michelle Araújo. Lazer e amizade na infância: implicações para saúde, educação e desenvolvimento infantil. Psicologia da Educação, n. 36, p. 83-92, 2013. Disponível em: http://pepsic.bvsalud.org/pdf/psie/n36/n36a08.pdf. Acesso em: 02 jan. 2018. http://dx.doi.org/10.1590/S0103-863X2008000300014

VALADEIRO, Carina Alexandra do Nascimento. As relações de amizade entre as crianças na creche e no jardim-de-infância. Dissertação (Mestrado em Educação Pré-Escolar). Instituto Politécnico de Setúbal. Escola Superior de Educação. Setúbal, Portugal, p. 116, 
DOI: $10.12957 / \mathrm{e}-\mathrm{mosaicos} .2021 .50162$

2017. Disponível em: https://comum.rcaap.pt/handle/10400.26/19671 . Acesso em: 02 jan. 2018. http://dx.doi.org/10.1590/S0103-863X2008000300014.

VIGOTSKI, Lev Semionovitch. A formação social da mente. 5. ed. São Paulo: Martins Fontes, 1994.

WISNIEWSKI, Maurício-UFPR; TOLENTINO, Patricia Caldeira-UEPG. As relações de amizade na infância: fator de socialização e desenvolvimento pessoal. In: $X$ Congresso Nacional de Educação-EDUCERE. 2011. Disponível em http://educere.bruc.com.br/arquivo/pdf2011/4478_3950.pdf. Acesso em dezembro de 2018

Recebido em 15 de abril de 2020

Aceito em 15 de março de 2021

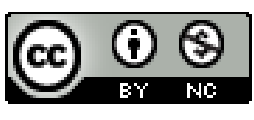

A e-Mosaicos Revista Multidisciplinar de Ensino, Pesquisa, Extensão e Cultura do Instituto de Aplicação Fernando Rodrigues da Silveira (CAp-UERJ) está disponibilizada sob uma Licença Creative Commons - Atribuição - NãoComercial 4.0 Internacional.

Os direitos autorais de todos os trabalhos publicados na revista pertencem ao(s) seu(s) autor(es) e coautor(es), com o direito de primeira publicação cedido à e-Mosaicos.

Os artigos publicados são de acesso público, de uso gratuito, com atribuição de autoria obrigatória, para aplicações de finalidade educacional e não-comercial, de acordo com o modelo de licenciamento Creative Commons adotado pela revista. 